\title{
EI Nuevo Teatro Español. La crítica del sistema político y social en Antonio Martínez Ballesteros y Miguel Romero Esteo
}

KLAUS PÖRTL

Universidad de Maguncia

Desde hace algunos años se designa con el nombre de Nuevo Teatro Español a un grupo de dramaturgos jóvenes poco conocidos todavía fuera del círculo de los expertos e iniciados a pesar de algunos libros, artículos e incluso bibliografías recientes sobre el tema ${ }^{1}$ y a pesar de algunos estrenos de estos autores en los últimos años. El comienzo puede situarse en 1965 , pues en este año George E. Wellwarth, que puede considerarse hoy como el verdadero descubridor de este nuevo teatro, inició la serie de estudios que habían de concluir en su libro Spanish Underground Drama, aparecido en 1972, que se publicó más tarde, en 1978, en traducción española ${ }^{2}$.

1 L. Teresa Valdivieso, España: Bibliografía de un teatro «silenciado», Society of Spanish and Spanish-American Studies, 1979 (Véase también la tesis doctoral de la misma autora: Una aproximación semiológica al teatro clandestino español, Arizona State University, 1975).

2 El crítico de teatro George E. Wellwarth, profesor de la Universidad Estatal de Nueva York, en Binghamton, ha dado a conocer en diferentes estudios monográficos y antologías el Nuevo Teatro Español como fenómeno de la más reciente creación dramática española. Pueden verse las publicaciones de Wellwarth a este respecto: The Theater of Protest and Paradox. Developments in the Avant-Garde Drama, Revised Edition, New York, Mac Gibbon \& Kee, 1971. En esta segunda edición, Well- 
El profesor americano Wellwarth viajó por España, recogió material y entrevistó a los entonces jóvenes autores. A su actividad se deben, en parte, los contactos ulteriores de los dramaturgos entre sí. En 1965, por otra parte, se reunieron por primera vez los dramaturgos de este grupo en la Sorbona de París, de manera que, retrospectivamente, existen razones justificadas para situar en esta fecha el comienzo del Nuevo Teatro Español ${ }^{3}$.

El tema central, a manera de hilo conductor a través de la mayor parte de las obras, es la crítica del sistema político y social bajo la dictadura de Franco. Todos estos autores han tenido que luchar con idénticas dificultades. Han querido expresar en el escenario sin reserva alguna, como teatro de oposición, su malestar ante las circunstancias de su país, pero, claro está, no les fue permitido. La resistencia ante su protesta procedía por una parte de las instituciones establecidas. Los teatros no subvencionados de Madrid y Barcelona, orientados hacia la ganancia financiera, ignoraron más o menos el Teatro Nuevo ${ }^{4}$. Por esta causa, la mayoría de las obras no sólo no se publicaron, sino que ni

warth ha añadido a la primera de 1964 un capitulo nuevo sobre el teatro español de protesta. En la traducción española de esta edición (Teatro de protesta y paradoja. La evolución del teatro de vanguardia, Barcelona, Madrid, Alianza Editorial, 1974), sin embargo, está ausente esta adición, obviamente por razones de censura, como el editor indica lapidariamente en nota al prólogo (op. cit., p. 11). -Spanish Underground Drama, Pennsylvania, The Pennsylvania State University Press, 1972. -Modern Spanish Theatre: An Anthology of Plays, New York, The New York University Press, 1969. - The New Wave Spanish Drama. An Anthology, New York, The New York Univ. Press, 1970. - New Generation Spanish Drama. An Anthology, Montreal, Engendra Press, 1976. La polémica del crítico y dramaturgo José María Rodríguez Méndez contra Wellwarth como el descubridor extranjero del Nuevo Teatro Español carece ciertamente de justificación (véase J. M. Rodríguez Méndez, «Las paradojas de Mister W.», in J.M. R. M., Comentarios impertinentes sobre el teatro español, Barcelona, Península, 1972, 98-101). Puede verse también «George Wellwarth», in Amando Carlos Isasi Angulo, Diálogos del teatro español de la postguerra, Madrid, Ayuso, 1974, 499-504, y Alberto Miralles, Nuevo teatro español: una alternativa social [sic], Madrid, Villalar, 1977, 35 ss. El mismo Miralles ha prologado y actualizado la traducción española de Spanish Underground Drama, que apareció con seis años de retraso (véase A. Miralles, in George E. Wellwarth, Spanish Underground Drama. Teatro español underground, Madrid, Villalar, 1978, 11-31.

3 Véase igualmente el estudio de Andrés Franco: «Apuntes sobre el 'Nuevo Teatro Español'», Ínsula 323 (1973), 1 y 14-15. Franco ofrece sobre todo una síntesis muy útil de las conclusiones fundamentales de los estudios de Welwarth.

4 Sobre la desolada situación en que se encuentra el teatro español actual, también después de la muerte de Franco, porque no ha cambiado casi nada, puede verse el 
siquiera fueron representadas. Si ocasionalmente teatros experimentales o de estudiantes representaban con grandes dificultades alguna de estas obras, la arbitraria censura teatral estaba invariablemente en contra ${ }^{5}$. Los autores del Teatro Nuevo han encontrado asimismo otro obstáculo serio a su producción en el Establishment de crítica y público, que constituye un bloque monolítico en el sistema teatral español y está limitado socioculturalmente a Madrid y Barcelona ${ }^{6}$. Esta constelación sociocultural no ha cambiado mucho aun después de Franco, si prescindimos de la irrupción de sexo y política en el teatro, que ha originado el famoso destape.

\section{Wellwarth enumera en su estudio Spanish Underground Drama 12}

Informe ampliamente documentado y que ilumina diversas zonas de la actividad teatral: El espectáculo de la huelga. La huelga del espectáculo, Madrid, Ayuso, 1974. Véase también la referencia sobre la situación del teatro español de Javier Maqua y Alberto Fernández Torres: «¿Dónde va el teatro? Catástrofe o reliquia?», Pipirijaina 2 (1976), 22-25. Véase María Pilar Pérez-Stansfield, Direcciones del teatro español de posguerra: Ruptura con el teatro burgués y radicalismo contestatario, Madrid, J. Porrúa Turanzas, 1983. Remito también a dos tesis doctorales, que se han hecho recientemente en la República Federal de Alemania: Barbara-Sabine Kulenkampff, Theater in der Diktatur. Spanisches Experimentier-theater unter Franco, München, Kitzinger, 1979, y Mario Saalbach, Spanisches Gegenwartstheater. Unterdrückung und Widerstand im Endstadium der Franco-Diktatur, Bonn, Bouvier, 1984.

5 Es interesante en este contexto la encuesta que la revista de teatro Primer Acto hizo a 25 dramatugos, algunos de ellos pertenecientes al teatro de protesta, sobre su actitud frente a la censura teatral y los efectos de la misma: Amador Rivera y S. de las Heras, «Encuesta sobre la censura. 25 autores cuentan sus experiencias con la censura», Primer Acto 165 (1974), 4-14, y S. de las Heras y A. Rivera, «Encuesta sobre la censura. Otros 14 autores cuentan sus experiencias», Primer Acto 166 (1974), 4-11. Sobre las dificultades que había con la censura en los primeros años de la nueva democracia, véase entre otros: Ángel García Pintado: «Una inmodesta proposición: censores para la reforma», Pipirijaina 1 (1976), 44-45; A. García Pintado, «El franquismo explica la censura», Pipirijaina 6 (1978), 46-45; Alberto Miralles, «Los tiempos están cambiando», Pipirijaina 7 (1978), 56-60; A. Miralles, «La censura que no cesa. Juzgado de guardia. El contagio de la paranoia», Pipirijaina 8-9 (1978), 54-57. La problemática entera trata entre otros Manuel L. Abellán, Censura y creación literaria en España (1939-1976), Madrid, Edicions 62, 1980.

6 Son muy iluminadores en este aspecto los estudios recientes sobre el mecanismo del sistema cultural durante la era de Franco: Georgina Cisquella, José Luis Erviti \& José A. Sorolla, Diez años de represión cultural. La censura de libros durante la Ley de Prensa (1966-76), Barcelona, Laia, 1977. Castilla del Pino y otros, La Cultura bajo el franquismo, Barcelona, Laia, 1977. Jesús García Jiménez, Radiotelevisión y política cultural en el franquismo, C.S. I. C., Madrid, 1980. Antonio Bonet Correa y otros, Arte del franquismo, Madrid, Cátedra, 1981. 
autores pertenecientes al reducido círculo del teatro de protesta ${ }^{7}$. Que actualmente se sepa, el número de los dramaturgos contestatarios de lengua española se eleva a unos $20^{8}$, si bien faltan aún estudios específicos sobre autores concretos, que podrán darnos una información más precisa ${ }^{9}$.

Metodológicamente aparecen problemas considerables. Así por ejemplo, Francisco Ruiz Ramón, en su amplia e indudablemente valiosa Historia del Teatro Español del Siglo $X X$-me refiero a la segunda edición aumentada de 1975- ha incluido y tratado juntamente con el Nuevo Teatro a la llamada generación realista, algunos de cuyos representantes son Antonio Gala, José Martín Recuerda, Carlos Muñiz, Lauro Olmo, Ricardo Rodríguez Buded, José María Rodríguez Méndez y Andrés Ruiz. Con la contraposición Nuevo Teatro Español, incluida la generación realista, por una parte, y teatro actual oficial o comercial, por la otra, se difuminan excesivamente en la obra de Ruiz Ramón las grandes diferencias que existen también dentro de la generación dramática joven ${ }^{10}$. Creo, pues, que es más adecuado hablar en lo sucesivo de teatro de protesta y crítico del sistema político en sentido estricto, cuando nos referimos al grupo de dramaturgos de protesta. Finalmente, la mayoría de los autores de la generación realista están integrados de alguna

7 Prescindiendo de los autores exiliados José Martín Elizondo y José Guevara, Wellwarth estudia individualmente a los siguientes dramaturgos de protesta: (1) José María Bellido, (2) Juan Antonio Castro, (3). Ángel García Pintado, (4) Jerónimo López Mozo, (5) Antonio Martínez Ballesteros, (6) Manuel Martínez Mediero, (7) Luis Matilla, (8) Eduardo Quiles, (9) Miguel Ángel Rellán, (10) Miguel Romero Esteo, (11) José Ruibal, (12) Diego Salvador.

8 En una relación más precisa de los dramaturgos españoles de protesta se debe incluir, además de estos 12, a los siguientes autores: Daniel Cortezón, Miguel Ángel Medina Vicario, Alberto Miralles, Francisco Nieva, Luis Riaza y Hermógenes Sainz. En el Apéndice de la segunda edición de su Historia del Teatro Español. Siglo XX, Madrid, Cátedra, 1975, 573-574, F. Ruiz Ramón señala algunos otros autores que tal vez se incluirán dentro del teatro español de protesta. La Biblioteca y Museo del Instituto del Teatro de la Universidad de Purdue tiene una colección de material inédito de dramaturgos españoles de protesta preparada por Francisco Ruiz Ramón. Puede verse la lista de los manuscritos de que dispone en «Manuscritos del Teatro Español», Estreno I, 1 (1975), 36-40.

9 Destaco aquí el libro ya citado de Mario Saalbach (ver nota 4) que trata en especial de J. López Mozo y Luis Matilla, así como a Elda María Phillips, Idea, signo y mito en el teatro de José Ruibal, Madrid, Orígenes, 1984.

10 Francisco Ruiz Ramón, Historia del Teatro Español. Siglo XX, Madrid, Cátedra, 1975,485 ss. 
manera en el teatro comercial, lo cual, hasta hoy, casi no se puede afirmar de los autores del teatro de protesta a excepción de algunos casos aislados (p.e. Martínez Mediero).

Si tenemos en cuenta el teatro de protesta y crítico del sistema político de Antonio Martínez Ballesteros, podemos observar que su obra hasta el presente ilumina la situación de todo el grupo. He aquí sus características: pocas publicaciones, y parte de estas pocas, en traducciones extranjeras; representaciones ocasionales, al margen del programa teatral oficial, y una multitud de manuscritos dramáticos sin publicar ${ }^{11}$. Desde 1960 Antonio Martínez Ballesteros ha escrito unas 40 obras dramáticas de uno o más actos, de las cuales hasta ahora bastante menos de la mitad han podido publicarse en España ${ }^{12}$.

11 Pueden consultarse las críticas resumidas de teatro de Francisco Álvaro que aparecen anualmente desde 1959: El espectador y la crítica. (El teatro en España en 1958 y ss,), Valladolid, Sever-Cuesta; Madrid, Prensa Española, 1959 y ss. El papel de outsider de los dramaturgos de protesta dentro de la actividad teatral diaria resalta claramente a la vista de las estadísticas presentadas y de las representaciones alabadas por la crítica en cada uno de los volúmenes publicados.

Esta cifra se basa en la relación cronológica de la producción teatral de Martínez Ballesteros hasta el presente. Las obras publicadas aparecen entre paréntesis; de lo contrario se trata de manuscritos inéditos: Orestíada 39, 1960; Los mendigos, 1961; El pensamiento circular, 1962-63; Un incidente sin importancia, 1962; En el país de Jauja, 1963 (The Best of All Possible Worlds, in Wellwarth, The New Wave Spanish Drama, New York, The New York University Press, 1970); El héroe, 1964 (The Hero, in Wellwarth, o.c.); Relato frívolo de una mujer fría, 1965; Las gafas negras del Señor Blanco, 1966; Los comediantes, 1967, redacción refundida en 1982; Sancho Español, 1967; El camaleón, 1967; La farsa de Salsipuedes, 1968; Retablo infantil, 1968; El patio de Monipodio, 1968; Los peleles, 1969 (in Teatro difícil, Madrid, Escelicer, 1971, y The Straw Men, in Modern International Drama III, 1969); Farsas contemporáneas, 1969: La opinión (Yorick 39, 1970); Los esclavos (Yorick 39, 1970); Los opositores (Primer Acto 119, 1970); El hombre-vegetal (juntamente con las tres obras anteriores, Madrid, Escelicer, 1970, Colección Teatro); Retablo en tiempo presente, 1970; La colocación (The Position, in Modern International Drama IV, 1971); La distancia (in Teatro difícil, Madrid, Escelicer, 1971); El silencio, El soplo (juntamente con las tres obras anteriores, Madrid, Escelicer, 1972, Colección Teatro); La improvisación, 1970; Las bicicletas, 1971 (in Fablas 33, 1972); El superviviente, 1971 (Primer Acto, 1971); El orden chino, 1971; Los primates, 1971; El tranquilizante, 1972; Fábulas zoológicas, 1972 (1. ${ }^{a}$ redacción); Romancero secreto de un casto varón, 1972 (Madrid, Fundamentos, 1976); Las siete flaquezas de un varón ibérico, 1973; Los placeres de la egregia dama, 1973 (Estreno I, 3, 1975)); A lo alto y a lo bajo, 1974; La boda, 1975; Fábulas zoológicas, 1975 (2. ${ }^{2}$ redacción, Madrid, Fundamentos, 1976); El juego de la medalla, 1976; Sultanísimo por la gracia de Alá, 1976; Réquiem por un mamífero nostálgico, 1977; La ocultación, 1977; Volverán banderas victoriosas, 1977; La utopía de Albana, 1979; Vacío de identidad, 1980 (?); Fabulilla de la peste, 1981 (?); Desde la cruz del norte o El maravillo- 
Nuestro autor nació en Toledo en 1929 y continúa viviendo en su ciudad natal, que no gusta de abandonar. Esta asombrosa autolimitación provinciana causa cierta extrañeza. Toledo carece de vida teatral, y para un dramaturgo significa en todo caso condenarse al aislamiento. El hecho de que a pesar de ello Ballesteros se destaque como un representante importante del teatro de protesta es explicado por Wellwarth como un fenómeno de talento dramático instintivo, del cual el autor no sería consciente ${ }^{13}$. Más extraña aún, si bien más cercana a la solución del enigma, es la aparente incompatibilidad entre profesión burguesa y actividad de escritor en Martínez Ballesteros. Ballesteros es un empleado, a nivel subordinado, en una empresa estatal de seguros en Toledo, y su mujer lleva una tienda de artículos de artesanía toledana. ¿Quién iba a sospechar tras esta burguesía acomodada y de buena situación, la existencia de un autor serio de protesta? Esta especie de escisión esquizoide, que recuerda un poco a Kafka, tiene, sin embargo, una explicación. Martínez Ballesteros confiesa que posiblemente él no hubiera escrito jamás, si no hubiera experimentado cada día, en sí mismo y en la maquinaria socio-profesional, la suerte del hombre humilde tratado despectivamente desde arriba, la suerte del garbanzo negro, según su misma expresión ${ }^{14}$. El autor elabora, pues, sobre la propia experiencia de su mundo profesional, casos ejemplares, casos modelo, para un teatro que proyecta desde sí mismo hacia un nivel universal las circunstancias políticas, sociales y culturales que constituyen la problemática del hombre que se siente constantemente pisoteado y que se debate en la tenaza de la dependencia de otros.

Esta génesis autobiográfica de su teatro, como me gustaría llamarla, puede verse con toda claridad en las Farsas contemporáneas y en la sección Rarezas del Retablo en tiempo presente. Estas escenas gráficas y piezas en un acto desarrollan temáticamente la existencia de un mal radical, una situación abusiva, una injusticia, y reflejan a modo

so cambio del señor Timón, 1983 (se trata de una redacción refundida de Las gafas negras del señor Blanco).

13 George E. Wellwarth, Spanish Underground Drama, The Pennsylvania State University, 1972, 38.

14 Según carta de A. Martínez Ballesteros a Christel Haack, con fecha 15 de julio de 1975. Véase la tesina de la Facultad de Lingüística Aplicada de la Universidad de Maguncia, en Germersheim, de Christel Haack: José Ruibal und Antonio Martínez Ballesteros. Untersuchungen zum Teatro Nuevo in Spanien, 1974 (Tesina de la Facultad de Lingüística Aplicada de la Universidad de Maguncia). 
de paradigma las dolorosas observaciones del autor sobre su medio ambiente. Martínez Ballesteros llama a su obra La opinión una Farsa contra la violencia y ataca en ella la opresión y manipulación de la libertad de opinión. El hombre vegetal es denominada por él una Farsa contra el conformismo y representa a un conformista que vegeta como un animal. La colocación es, según Martínez Ballesteros, una Rareza, donde el autor desvela conjunciones extrañas entre la educación autoritaria y la adherencia inflexible a un mundo profesional jerárquicamente estructurado e inmutable. En las obras más largas, de dos o tres actos, Martínez Ballesteros describe excrecencias abusivas del poder contra los oprimidos políticamente, contra los que tienen limitados sus derechos fundamentales, dentro del entramado de un comportamiento resignado, oportunista o revolucionario. Esta dimensión aparece claramente en las obras de La trilogía contra la opresión, es decir En el país de Jauja, El héroe y El camaleón.

La conexión actual con la realidad política y social de España bajo Franco aparece muy claramente en todas las obras de Martínez Ballesteros, a pesar de que - o justamente porque - el autor hace uso de la alegoría o de la parábola (p.e., en Fábulas zoológicas), o traspone el acontecer a un mundo imaginario (La trilogía contra la opresión) o recurre al pasado (así p.e., El tranquilizante y Los secuestros). Este procedimiento de velar y encubrir expresiones directas y de alusiones a realidades actuales inmediatamente inteligibles para los iniciados es una reacción obligada ante las normas vigentes de la censura teatral en la era franquista. Ésta se basaba en la nueva redacción de la censura cinematográfica de 1963 y prohibía la crítica abierta de la moral y de la sociedad, de la religión y de la práctica de la misma, así como del orden estatal y de sus representantes ${ }^{15}$. El autor crítico del sistema político ha de

15 Como todos los dramaturgos que han querido representar en España durante el gobierno de Franco, los autores del teatro de protesta han tenido que someterse a las Normas de Censura Teatral formuladas conjuntamente con las Normas de Censura Cinematográfica según Orden Ministerial del 9 de febrero de 1963 y publicadas en el Boletín Oficial del Estado del 8 de marzo de 1963. La competencia de la Junta de Censura de Obras Teatrales fue fijada respectivamente por Orden Ministerial del 6 de febrero de 1964 y formulada nuevamente a 27 de octubre de 1970. Sobre el problema de la censura, aparte de lo que se dijo en la nota 5 , véase la documentación ya citada El espectáculo de la huelga. La huelga del espectáculo, Madrid, Ayuso, 1976, 365 y ss., así como Pedro Jiménez: «Apuntes sobre la censura durante el franquismo», Boletín de la Asociación Europea de Profesores de Español 17 (1977), 3-8. La censura teatral y cinematográfica no fue abolida antes de principios del año 1978 por decreto. 
recurrir, por lo tanto, a un simbolismo aparentemente limpio de toda sospecha. El sociólogo Elías Díaz ha observado con cierta preocupación cómo este tipo de encubrimiento forzado llevaba a efectos negativos para todo un grupo cultural, y afirma en este contexto: «Y la traumatizante autocensura y los usos del criptolenguaje, del leer y escribir entre líneas, siguen causando efectos perniciosos en la cultura y en las mentes de los españoles ${ }^{16}$. En los años 70 Martínez Ballesteros ha escrito un conjunto de sátiras que, según sus mismas palabras, no tenían ninguna oportunidad de ser representadas. La crítica velada era demasiado visible en ellas. A este grupo pertenecen las dos malignas invectivas contra Franco, Los placeres de la egregia dama y Sultanísimo por la gracia de Alá. En Los placeres de la egregia dama, Franco y su esposa están representados en la pareja Anastasia y Federico. Entre las alusiones satíricas a Franco están la victoria de la guerra civil y la impotencia resultante de las heridas recibidas en ella, y en lo que se refiere a su mujer, el ansia de honor y aplauso por parte del pueblo a modo de sustitutivo del orgasmo que no consigue con su marido. Al final de la obra, en el mundo invertido de la sátira, se ve a la mujer embarazada, esperando, como mujer que va a dar a luz, al hijo engrendrado por el pueblo. La sátira es mucha más visible aún en Sultanísimo por la gracia de Alá, que Martínez Ballesteros escribió en 1976 bajo la impresión reciente de la muerte del dictador. Estas obras han de considerarse hoy sobre todo como un documento que muestra cómo un dramaturgo español de protesta atribuye el mal radical a Franco, todas las frustraciones y angustias acumuladas a lo largo del tiempo. Es una sátira personal, ocasionalmente de mal gusto.

Las parábolas animales son un género preferido de crítica encubierta. Martínez Ballesteros describe circunstancias españolas bajo Franco en la parábola animal Fábulas zoológicas, grotescamente disfrazada con el rótulo de Comic del mundo animal en dos partes. Voy a hablar en primer lugar de la primera redacción existente sólo en manuscrito. En

Elías Díaz, Notas para una historia del pensamiento español actual [1939-1973], Madrid, 1974, 167 (nueva edición: Pensamiento español en la era de Franco [1939-1975], Madrid, Cuadernos para el Diálogo, 1983). Puede verse también Fernando Arrabal, el cual provocó cierto escándalo con su Carta al General Franco, París, Unión Générale d'Editions, 1972, y «Cartas a Franco y al Rey», Pipirijaina 3 (1976), 4-7. Véase también el comentario resumido sobre la situación de los dramaturgos españoles después de casi cuarenta años de censura bajo el dominio de Franco, de Fernando Arrabal: «La alienación franquista», Estreno II, 1 (1976), 11-13. 
la primera parte de la parábola dos parejas de perros representan simbólicamente la lucha contra la opresión. Sus opresores son los hombres de la clase dominante. Después de la revolución zoológica, el hombre es expulsado de la tierra, pero los animales, una vez liberados, imitan por su parte el orden humano que está organizado en clases o estratos en un sentido vertical. Al frente, en la cúspide, está El Gran Caporal, seguido de Los Caporales, Los Caporalitos y Los Caporalines. Salta inmediatamente a la vista la equiparación satírica de los Caporales con la organización del estado franquista. El doble filo de la ironía en la parábola se basa en el juego verbal con el significado múltiple de caporal: caporal expresa inicialmente una categoría o rango militar, y también, en lenguaje de germanía, gallo o ave. Así tenemos un gallinero al mando de un gallo. La segunda parte de la obra contiene trozos de la Era de la civilización zoológica, en la cual los Linces y Sabuesos poseen el poder juntamente con Míster Búldog. El simbolismo animal se puede descifrar también fácilmente en esta composición: lince expresa la astucia de los políticos y sabuesos, el perro rastreador de fino olfato es el vocablo en cifra para el omnipotente aparato policial. El interrogatorio de un estudiante en figura de chivo despliega todo el temario de conceptos tabú y palabras irritantes de la política española bajo Franco, tales como actitud frente a la guerra civil, el problema de las asociaciones políticas como sustitutivo de los partidos, terrorismo y uso de la fuerza, derecho a la huelga, relaciones Iglesia-Estado. Martínez Ballesteros ha incorporado a la segunda redacción de Fábulas zoológicas su obra anterior Los primates, de 1971, y ha ampliado la segunda parte de la primera redacción que acabamos de describir ${ }^{17}$. El autor comiènza ahora literalmente $a b$ ovo: los hombres -él y ella- salen de un huevo gigante y son adoctrinados sucesivamente en una secuencia de cámara rápida. Desde arriba, una voz les proporciona el habla y el comportamiento social justo, siempre a través de conceptos fundamentales de sentido vertical, como «mentira-verdad», «mandar-obedecer», «maldad-bondad». La palabra mágica que se intercala una y otra vez. es comunicación. El tema básico es la manipulación del hombre por el hombre en este comic tipológicamente nuevo en España desde el punto de vista dramático-tipológico. El medio apropiado para ello es la lengua con sus posibilidades de ocultación, de donde resulta que siempre se puede ocultar la verdad con miras a la ventaja propia.

17 Antonio Martínez Ballesteros, Fábulas zoológicas. «Comic» del mundo «animal» en dos partes, Madrid, Fundamentos, 1976 (Cuadernos prácticos, 21). 
Las parábolas políticas de Martínez Ballesteros son diagnósticos sencillos sobre circunstancias concretas sin pathos revolucionario. El autor ejerce ciertamente su crítica sobre las circunstancias existentes, es decir, sobre el sistema, pero no ofrece como contrapartida un ideal revolucionario o utópico. Quiere simplemente hacer una llamada a la conciencia y mayoría de edad políticas, pero no pretende agitar con propaganda partidista, en el sentido, p.e., de Alfonso Sastre. El revolucionario, según Martínez Ballesteros, es o corrompido o excesivamente débil. La figura del variable Camaleón, en El país de Jauja, muestra a un antiguo revolucionario que se ha transformado en el partidario más fiel de la dictadura que había anteriormente combatido. Le han tapado a tiempo la boca, pues sus ideas subversivas no eran nada más que el resultado de un estómago vacio. El protagonista de El héroe, Juan Pobre, es un hombre destrozado después de una larga cautividad política y no quiere saber nada de la revolución. Es proclamado héroe nacional, porque en la lucha ha matado por equivocación a un partisano amigo. Estos dos ejemplos muestran igualmente un simbolismo nominal fácilmente reconocible: el inconsistente Camaleón es un camaleón, el antihéroe Juan Pobre, carente de voluntad, es simplemente un pobre Juan o un Juan Lanas.

Nuestro dramaturgo utiliza intencionadamente una serie de medios expresivos extralingüísticos paraverbales con carácter de estereotipo ${ }^{18}$. Entre ellos habría que considerar en primer lugar la presentación intencionadamente exagerada de objetos convertidos en símbolos. Quisiera designar esta técnica con el nombre de simbolismo hiperbólico de los recursos escénicos. Ejemplos: en La colocación, el hombre aparece sentado siempre sobre largas puntas, con lo cual se pone drásticamente de relieve la costumbre gradual a las durezas e injusticias de la vida. O con otro ejemplo: en La distancia el extrañamiento mutuo de un matrimonio se representa gráficamente con la división de una cama, que imperceptiblemente se desintegra al final de cada diálogo. En consonancia con este simbolismo de los recursos está la simplificación extremada de los problemas con un carácter didáctico. Con ello se quiere tener en cuenta las posibilidades de comprensión de un público poco educado o ca-

18 Merecería la pena estudiar en los distintos autores de protesta los elementos extralingüísticos señalados por Luciano García Lorenzo en el teatro de A. Buero Vallejo («Elementos paraverbales en el teatro de Antonio Buero Vallejo», en José M. ${ }^{a}$ Díez Borque y Luciano García Lorenzo, Semiología del teatro, Barcelona, Planeta, 1975, 103-125). 
rente en absoluto de formación. Es decir, se pretende hablar a un público ajeno al teatro que de otro modo no iría nunca a él. Martínez Ballesteros abstrae de un problema unas pocas causas principales y sus efectos. Por ejemplo, en Las bicicletas, simplifica la complicada dependencia del hombre con respecto al sistema de consumo que él mismo se ha creado con el rápido pedaleo de los ciclistas a destajo en una bicicleta de prácticas. Los explotadores son los jueces con su sistema de supervisión y control, los explotados son los ciclistas. El que no entra en el juego, se queda sin nada.

Estos medios expresivos llevan a la esquematización de la acción dramática. Por ejemplo, en Los esclavos, Martínez Ballesteros expone, en una acción gráficamente abreviada, la relación entre explotadores y explotados desde el comienzo de la humanidad hasta hoy. Solamente una pareja a la vez, o sea, hombre número uno-mujer número uno, hombre número dos-mujer número dos, representa en cámara rápida la historia de la explotación del hombre por el hombre. Los personajes dramáticos representan funciones, no reflejan una vida interna individual. Es decir, en otras palabras, el teatro de protesta de Martínez Ballesteros apenas contiene elementos dramáticos de carácter sociológico. En la obra de Martínez Ballesteros se puede hablar de una despersonalización progresiva de las figuras dramáticas, a medida que sus obras se hacen más abstractas y doctrinales. Martínez Ballesteros limita también la lengua a una función de signo: es una lengua lapidaria, carente de humor, sin especificaciones. Los medios extralingüísticos adquieren en parte un rango equivalente; tales son, por ejemplo, los recursos escenográficos, la música, baile, máscaras, pantomima, montaje escenográfico visible, efectos sonoros con altavoces, etc. Ciertamente no debe buscarse una relación entre Martínez Ballesteros y Antonin Artaud, relación que sería más adecuada para otro representante del teatro español de protesta. Pienso sobre todo en el teatro cruel de un Manuel Martínez Mediero, con sus efectos de shock intencionales, como por ejemplo en El convidado ${ }^{19}$. Tampoco es posible hablar de un influjo visible de

Manuel Martínez Mediero: El convidado, in Teatro difícil, Madrid, Escelicer, 1971, 73-86. Otras obras como Las planchadoras (1970) o Las hermanas de Búfalo Bill (1971) de M. Martínez Mediero, publicada en 1974 (Madrid, Fundamentos, Cuadernos prácticos, 14) siguen también claramente la dirección del teatro cruel en la línea de Artaud. Sobre la recepción reciente de Artaud en España, véase el número de Primer Acto 159-60 (1973) sobre Artaud, especialmente F. Lázaro Carreter: «Artaud y el teatro contemporáneo» (13-21). El estudio aforístico de Ángel García Pintado sobre «Artaud, el espíritu, la vida, el tiempo» (26-28) muestra en qué medida los dramaturgos españoles se enfrentan con Artaud como un modelo a seguir. 
Bert Brecht en Martínez Ballesteros, a pesar de ciertos elementos épicos y alienantes de carácter brechtiano, visibles en los narradores, el cambio de papeles, el quebrar la ilusión. Podría ciertamente hablarse de una presencia visible de Brecht, por ejemplo, en el teatro de Angel García Pintado, sobre todo en su provocativa obra ;Laxante para todos! ${ }^{20}$.

En conclusión, podemos afirmar lo siguiente: Martínez Ballesteros utiliza conscientemente determinados medios de expresión dramática simplificados con la intención de que especialmente el espectador carente de formación pueda fácilmente reconocer su simbolismo, descifrarlo y reaccionar con la protesta. Aquí radica la provocación que el autor de protesta desea del público. Desde este punto de vista, el duro juicio de Ruiz Ramón sobre el teatro de Martínez Ballesteros parece equívoco. Ruiz Ramón lo considera como un teatro sin pretensiones, apto para un público culturalmente retrasado, en una situación anormal de transición dentro de la sociedad española. Hemos de preguntarnos, en primer lugar, qué criterios utiliza Ruiz Ramón en su juicio, y si tales criterios son adecuados. ¿Es posible juzgar a un escritor simplemente con las categorías estéticas al uso de una literatura con pretensiones intelectuales? Segunda pregunta: ¿se puede liquidar despectivamente la intención didáctica declarada del autor con vistas a un teatro para el pueblo como, en palabras de Ruiz Ramón, «el producto más auténtico de una sociedad culpablemente víctima [...] de un inefable y dramático proceso de castración intelectual»? ${ }^{21}$ Martínez Ballesteros ha tomado postura ante estos reproches que personalmente considero desmedi$\operatorname{dos}^{22}$. Como crítico literario, uno debería ser capaz de ver y valorar en consecuencia el hecho de que en los últimos diez o quince años del go-

20 En Ángel García Pintado pueden apreciarse influencias tanto de Artaud (por ejemplo en La crucifixión, 1968, o en Agonía de Julián Despojos, 1972-73), como de Brecht (véase la obra iLaxante para todos!, 1973, que Moisés Pérez Coterillo considera como teatro de transgresión (Pipirijaina, 2, 1976).

21 F. Ruiz Ramón: op. cit., 559.

22 En carta a Christel Haack del 17 de marzo de 1976 escribe Martínez Ballesteros: «Por algo mi teatro es la clase de teatro que no quieren determinados críticos, con unos esquemas hechos de antemano [...] Yo sé que mi teatro interesa al público y que éste no se aburre. Hay muchos que creen que una manera de pasar por inteligentes es rechazar lo que llega fácilmente a la gente. Allá ellos. Hay un teatro facilón para halagar los instintos más bajos del público, y estamos todos de acuerdo en rechazarlo. Hay otro teatro, aparentemente fácil porque llega con facilidad al espectador, pero que no es nada fácil de hacer, con una dignidad crítica y una serie de inquietudes, que creo que es el que yo cultivo. No es fácil establecer esa comuni- 
bierno de Franco, Martínez Ballesteros ha intentado, de una manera peculiar y valiente, acercarse al pueblo, al hombre de la calle que no tiene el lastre de la cultura entendida como artículo burgués de consumo. Por otra parte, está evidentemente el hecho de que el efecto esperado fue muy local o reducido a causa de las restricciones existentes.

La situación del otro dramaturgo de protesta que analizamos en el presente estudio es completamente diferente. El andaluz Miguel Romero Esteo nació en 1930. Desde 1965 escribe obras de teatro que fueron prohibidas por la censura en su mayoría, y algunas, aun después de la era de Franco. Ésta es la razón de que sus obras hayan sido representadas sólo en casos de excepción, y de que sólo algunas de éllas hayan sido publicadas posteriormente ${ }^{23}$. Dentro del teatro de protesta Romero Esteo es considerado como excéntrico y enfant terrible, a consecuencia de los escándalos que provocó con sus obras Pontifical (1966), Paraphernalia de la olla podrida, la misericordia y la mucha consolación (1971) y Pasodoble (1973). Su segunda obra, Pontifical, que envió al Festival del Teatro Nuevo en Sitges, en 1966, provocó en el jurado una enconada lucha entre fieles al régimen y neoliberales. Esta grotescomaquia de 450 páginas, con cascadas inagotables de palabras diáfanas y de una liberalidad sin límites, que no conoce frontera alguna de eso que se llama buen gusto, traspasa todos los límites temporales de una representación teatral, pues duraría, sin cortes, 8 horas. El shock provocado en los expertos y la inmediata prohibición de la censura contribuyeron a que Pontifical circulara secretamente entre los estudiantes en ejemplares multicopiados y se convirtiera en símbolo del teatro opri-

ción, y eso fastidia al que no sabe hacerlo. En resumen, hay cosas aparentemente fáciles, pero que no lo son tanto.» (Sobre Haack véase la nota 14; las cartas de A. Martínez Ballesteros las guardo en el Archivo del Nuevo Teatro Español que tenemos en la Facultad de Lingüística Aplicada de la Universidad de Maguncia, Sección Española).

23 La lista de las obras de Romero Esteo incluye actualmente, según datos del autor, las siguientes: Pizzicato irrisorio y gran pavana de lechuzos, 1965 (Madrid, Cátedra, 1978); Pontifical, 1966; Patética de los pellejos santos y el ánima piadosa, 1970; Paraphernalia de la olla podrida, la misericordia y la mucha consolación, 1971 (edición incompleta in Estreno I, 2, 1975, T1-T32); Pasodoble, 1971 (Primer Acto 162, 1973, 15-49); Fiestas gordas del vino y el tocino, 1972-73 (Madrid, Ediciones Júcar, 1975); El vodevil de la pálida, pálida, pálida, pálida rosa, 1975 (Madrid, Fundamentos, 1979); El barco de papel, 1976; Horror vacui, 1974-83; Tartesos, 1976-83 (Pipirijaina 26-27, 1983, 32-341). Para más detalle véase la documentación en Pipirijaina 26-27 (1983), 22-23. 
mido de protesta ${ }^{24}$. Las olas de la conmoción se extendieron hasta Alemania, pues la editorial de teatro Suhrkamp descubrió en Romero Esteo un nuevo genio dramático español, se aseguró los derechos de autor para obras ulteriores y preparó una traducción de Pontifical $^{25}$. El estreno previsto de la obra en alemán para la inauguración del Nuevo Teatro de Basilea no llegó a realizarse. El teatro total de Romero Esteo resulta en su forma presente casi imposible de representar y origina tales dificultades para conseguir una escenificación adecuada que es preferible renunciar a ello ${ }^{26}$. Más tarde, sin embargo, Romero Esteo ha conseguido en España, según su propia información, un éxito considerable con El barco de papel (1975), en escenificación del grupo teatral Ditirambo. Representaciones hechas de una versión abreviada de Paraphernalia en Sitges (1972) y Madrid (1973) y de Pasodoble, también en Madrid (1974), produjeron un shock tanto en la crítica como en el público, es decir, tanto en los espectadores orientados hacia la derecha como hacia la izquierda ${ }^{27}$. Con la representación de $E l$ vodevil de la pálida, páli-

24 Puede verse la documentación bio-bibliográfica que el autor me ha proporcionado, incluida en el Apéndice de la tesina de Waltraud Ohlert, de la Facultad de Lingüística Aplicada de la Universidad de Maguncia en Germersheim: Spanisches Protesttheater bei Miguel Romero Esteo, 1977/78. Otras cuestiones de detalle y aspectos del propio teatro así como del teatro en general pueden verse en las diferentes entrevistas con Romero Esteo: «Diálogos a ritmo de pasodoble con Miguel Romero Esteo», Primer Acto 162 (1973), 6-11; Amando Carlos Isasi Angulo, Diálogos del teatro español de la postguerra, Madrid, Ayuso, 1974, 391-413; M. A. Medina Vicario, El teatro español en el banquillo, Valencia, Fernando Torres, 1976, 31-39. Véase también Francisco Álvaro, El espectador y la crítica. (El teatro en España en 1973), Madrid, Prensa Española, 1974, 228-230; Fernando Lázaro Carreter, «Crítica de dos obras de Miguel Romero Esteo», Estreno I, 2, (1975), 13-16; Pedro Aullón de Haro, «El texto del teatro: Miguel Romero Esteo», Revista de Literatura 83 (1980), 159-172, y Pedro Aullón de Haro, «La obra dramática de Miguel Romero Esteo», in M. Romero Esteo Tartessos, Pipirijaina, 26-27 (1983), 5-20.

25 Curt Meyer-Clason ha traducido Pontifical al alemán, en 1971, para la editorial Suhrkamp (distribuidora teatral), de Frankfurt.

26 El estreno, al parecer firmemente programado con motivo de la inauguración del Neues Schauspielhaus de Basilea y sobre el cual Romero Esteo gustaba de hablar en sus entrevistas, era considerado por los peritos competentes en materias de teatro únicamente como una «idea intensa», (Véase la correspondencia del Staatstheater de Württemberg con W. Ohlert en el Apéndice de la tesina de Ohlert, op. cit.). Una cosa es clara, y es que Suhrkamp considera apenas representable la redacción actual, y a lo sumo tendría en cuenta una redacción muy abreviada. En este contexto el traductor Meyer-Clason habla de un «cadáver viviente» (véase Ohlert, op. cit., Apéndice).

27 Véanse entre otras las críticas teatrales en la nota 24 , y la Breve autobiografía característica del genio peculiar del autor en el Apéndice de Ohlert, op. cit.; en el año 
da, pálida, pálida rosa Romero Esteo estrenó por primera vez en un teatro Comercial (Teatro de Jacinto Benavente, 5 de marzo de 1981). A pesar de la crítica más benévola que severa faltó pronto el público, sobre todo el público joven ${ }^{28}$. Romero Esteo parece no encajar dentro de ninguna dirección ideológica, lo cual suena a paradoja en este teatro de protesta en que el común denominador de todos los dramaturgos es la crítica del sistema político y social.

A la pregunta de si constituye para él algún valor ser considerado como representante del teatro de protesta, Esteo ha respondido negativamente ${ }^{29}$. Ha de ser catalogado, en todo caso, como solitario entre solitarios. En la medida de mis conocimientos, su producción hasta el presente constituye una ruptura más o menos completa con el movimiento oficial cultural y teatral, y no sólo dentro de España. Viene a mi recuerdo la filípica que lanza contra los sumos sacerdotes de la cultura en el prólogo a Fiestas gordas del vino y el tocino ${ }^{30}$. Con sus visiones grotescas de un teatro total, de un teatro que hace saltar en pedazos el palco reservado de la burguesía, Romero Esteo quiere liberar a los hombres de todas las coacciones que los dominan, es decir, quiere poner al hombre en libertad frente a todo lo que es represivo a sus ojos. Y para él, esto es sobre todo nuestra civilización actual, con todos los fenómenos concomitantes que ponen en peligro la vida — piénsese p.e., en las discusiones sobre los reactores atómicos-, las escalas fijas de valores de una sociedad determinada y sus fanatismos ideológicos. El instrumento de liberación de todas estas opresiones es la lengua, que Esteo utiliza de manera peculiar. Con el placer andaluz por la metáfora y las irregularidades de la lengua popular Esteo transforma la lengua en palabras y construcciones atrevidas y desconcertantes, fuerza sistemática-

1970 el autor apunta entre otras cosas: «Desde la izquierda teatral [...] mi nombre comienza a ser omitido y silenciado cada vez que se hable de teatro nuevo. La izquierda me borra de su lista de jóvenes autores (en la cual había yo comenzado a figurar a partir del escándalo del texto-mito Pontifikale en 1966).» (op. cit., 3).

Compare F. Álvaro, El espectador y la crítica. El teatro en España en 1981, Valladolid, Álvaro, 1982, 37-39.

Véase A. Carlos Isasi Angulo: op. cit., 409 y ss.

30

«... Hay otras muchas represiones. Son las ocultas, son las ocultas. Por ejemplo, a la hora de toda labor de creación, la gran presión y represión por parte de la maquinaria de la kultur - oh la kultur - la cual está en mano de los teoretas de turno [...] La burocratización del pensamiento. Cosa grave, y suave y oculta pugna entre el poeta y el teoreta...» (M. Romero Esteo: op. cit., 13). 
mente la expresión - un purista normativo diría que la viola - por medio de inversiones dirigidas a trastocar por completo la estructura de la lengua. Aquí ha de verse el punto de partida de su crítica del sistema político, que choca con la incomprensión de los lectores cultos, y en muchos casos, incluso con un violento rechazo.

Quiero resumir a continuación algunas de las características lingüísticas del teatro de Romero Esteo, limitándome básicamente a las aclaraciones que el autor me proporcionó con ocasión de la traducción de Pasodoble al alemán ${ }^{31}$.

(1) El estilo y el flujo de la exposición tienen un ritmo intenso. Las indicaciones escénicas son textos completos, no solamente meras referencias técnicas de teatro (Recuérdese especialmente a Valle-Inclán). Estas indicaciones no se distinguen del diálogo en cuanto al ritmo, y en parte rima, de la lengua, y hacen que la obra en conjunto sea un texto dramático completamente teatralizado.

(2) La rima, empleada frecuentemente como rima interna, distingue el diálogo con respecto a la prosa normal del teatro, sin convertirlo, no obstante, en verso, salvo en algunos casos intencionados. La rima surge espontáneamente y también con una preparación previa, buscada. El procedimiento es más o menos como sigue. El autor toma una palabra y la modifica en el sontido y articulación hasta casi provocar náusea, sin que el significado tenga frecuentemente importancia decisiva. Este juego ejercitado con frecuencia en una especie de pathos.pseudolitúrgico por medio de la repetición, continuación y ampliación de palabras, que suenan igual o de manera semejante, abre dimensiones nuevas de un mundo imaginario completamente irracional.

(3) La lengua está inundada de irregularidades sistemáticas. Constantemente aparecen irregularidades sintácticas, es decir, la sintaxis es desfigurada intencional y puntualmente con formaciones irregulares. De la misma manera encubre el autor el contenido semántico a través de

31 En carta dirigida a mí por Romero Esteo de fecha 24-6-1977 (en el Apéndice de la tesina de Ohlert, op. cit.). En el Apéndice están incluidas también la redacción corregida en 1976 del final de Pasodoble y algunas indicaciones a los traductores. En 1978 Signe Scheffzek y Dagmar Steffen, ambas de la Facultad de Lingüística Aplicada de la Universidad de Maguncia en Germersheim, han traducido Pasodoble al alemán para la editorial Suhrkamp (distribuidora teatral). Tampoco de esta obra hubo un estreno alemán hasta hoy día, a saber. 
fórmulas imprecisas. De este modo surge una estructura lingüística muy peculiar, que en la superficie aparece normal y debajo de la superficie acusa la presencia de un carácter psicopático a través de estas constantes disonancias, carácter que muestra un extraño estímulo poético. Podría decirse que un loco anda por aquí suelto, pero un loco con un sistema y con talento. O con otra comparación: podemos imaginarnos el concierto de una orquesta sinfónica en la que algunos instrumentos están intencionadamente desafinados. El autor logra la desfiguración sintáctica con el cambio de un verbo transitivo en intransitivo introduciendo la preposición de, cuyo uso constante ha llegado a ser en él una manía. En lugar de la formulación correcta yo te voy a dar tortas, el verbo transitivo dar se convierte en intransitivo intercalando la proposición de, en fórmula tomada de la conversación ordinaria, de donde resulta la frase: yo te voy a dar de tortas. El autor consigue el oscurecimiento de una frase igualmente con el uso irregular de preposiciones, intercambiando por, con, etc. En lugar de la frase correcta lloraba con melancolía y por amor, aparece en Romero Esteo lloraba de la melancolía y el amor. La introducción ocasional acá y allá del artículo determinado realza el efecto buscado de encubrir el significado, y por otra parte, la expresión resulta polivalente, porque la imprecisión hace posibles varias interpretaciones diferentes.

(4) Una expresión que parece inofensiva y de sentido único adquiere inesperadamente varios sentidos, por medio de ligeras modificaciones, entre las que destacan las alusiones erótico-sexuales, una vez más una especie de manía inconfundible de Romero Esteo. La asociación con los órganos genitales masculinos y femeninos o con actividades eróticas, frecuentemente marcadas con intensos rasgos sadomasoquistas, es una constante que aparece sin interrupción en los textos de Romero Esteo. Podemos aludir como ejemplo a un pasaje de Pasodoble. Primeramente aparece tú te mamas mi personalidad, que significa algo así como tú absorbes mi personalidad, tú te chupas mi personalidad vampíricamente. La frase tú te mamas mi personalidad es repetida varias veces, y en el proceso de la repetición el sustantivo femenino personalidad es sustituido por el pronombre la. La secuencia es como sigue: tú te mamas mi personalidad, tú te la mamas, tú te la mamas. Esta expresión pronominal asocia juntamente con su significado lógico derivado del contexto la expresión popular que alude a la fellatio.

(5) Niveles lingüísticos contrapuestos se funden forzadamente en una unidad. Lengua elevada y selecta cargada de vocabulario lírico y 
religioso-cultural choca con giros groseros vulgares, a nivel sintáctico y semántico. De aquí proceden las expresiones blasfemas y frases carentes de gusto o entendidas como una provocación. Romero Esteo ha recibido reproches especialmente en lo que se refiere a las primeras. Desde el punto de vista sociológico, en Romero Esteo se mezclan, al azar y por lo tanto forzadamente, produciendo una impresión grotesca, usos lingüísticos y vocabulario del burgués y del empleado, del pequeño burgués y del aristócrata con un lenguaje popular bajo, intensamente prohibitivo, procedente del estrato social de los trabajadores y campesinos. Estas colisiones dejan tras sí un vacío, es decir, en la fórmula de Romero Esteo, provocan implosiones en la estructura interna de la frase y de la lengua, y juntamente con las demás características estilísticas señaladas producen lo que el autor llama subversión idiomática. El paso de la subversión lingüística a la del contenido, es decir, a la crítica del significado, debe ser dado por el espectador que toma parte en el acontecer del teatro. Aquí está el complicado mecanismo de esta crítiea del sistema político bajo la superficie, de difícil acceso, y que, a diferencia de Martínez Ballesteros, sólo puede explicarse desde la estructura lingüística del autor ${ }^{32}$.

Al analizar las obras individuales de Romero Esteo no se puede partir de una acción. Se puede, más bien, hablar de sucesos estructurados $u$ organizados en secuencias, que se relacionan entre sí como las distintas partes de una tela de araña, según ha señalado Ruiz Ramón ${ }^{33}$. Las dramatis personae, entre las cuales figura también un papagayo en Pasodoble, tampoco tienen identidad individual. Romero Esteo teatraliza en forma abstracta luchas de individuos o de grupos entre sí. Sus obras tienen el carácter de una maquia, y se llaman grotescomaquia o tetralomaquia. La grotescomaquia de Pasodoble, por ejemplo, representa la ritual lucha por la existencia entre hombre y mujer en un matrimonio

32 En su carta ya citada del 24 de junio de 1977 Romero Esteo me decía en este contexto: «Para destruir algo, una implosión es mucho más eficaz que una explosión, mucha más demoledora. Algo así viene a significar subversión idiomática, criptodestrucción. Desde la cripto-infraestructura, es decir, desde la parte subterránea de la infraestructura lingüística (con respecto al lenguaje teatral) incluida la infraestructura idiomática (los materiales de base, tanto sintácticos como semánticos). Por otro lado, partir desde una racionalidad antagónica a la de las clases dominantes (burguesía, pequeña burguesía) que suele ser muy unilineal y mecánica, y partir desde criterios antagónicos y diametralmente opuestos a los criterios de las clases dominantes. Algo así trato de hacer yo».

33 F. Ruiz Ramón, op. cit., 567. 
específicamente español. La tetralomaquia Fiestas gordas del vino y el tocino muestra la lucha trágica de la naturaleza sometida contra la brutal civilización moderna. La princesa, como figura simbólica de la naturaleza, se yergue, contra la urbanización de su reino todavía intacto, frente a los enanos-gigantes humanos. Este fenómeno, que en su estructura externa recuerda los cuentos de hadas, está concebido como un teatro-fiesta para el teatro de la calle, pero un teatro de la calle que tiene dimensiones muy distintas de este tipo de teatro tal como aparece por ejemplo en la formulación teórica de Jerónimo López Mozo en su libro Teatro de barrio, teatro campesino (1976) ${ }^{34}$. Con sus múltiples rostros de dramaturgo elitista, dramaturgo tipo clown y dramaturgo del pueblo, Romero Esteo presenta un gigantesco aquelarre. A través de los diferentes elementos litúrgicos, musicales y de danza es quizá posible ver aquí un retorno o una orientación hacia formas teatrales rituales primitivas.

Al hacer pronósticos para el futuro, es obligada una mínima cautela. Sin embargo, es posible que en Romero Esteo tengamos uno de los grandes dramaturgos con los impulsos suficientes para llevar a cabo una renovación en el teatro que haga época. Romero Esteo tropieza con una total incomprensión por parte de sus contemporáneos debido a la fuerza impetuosa de su fantasía y la violencia de su lenguaje, como ocurrió con Valle-Inclán en su tiempo. Las obras producidas hasta el presente son, en todo caso, mucho más que una mera prueba de talento. Naturalmente, hemos de esperar la evolución ulterior. Valle-Inclán, que es el modelo común declarado de los autores de protesta, no había encontrado todavía la forma definitiva del esperpento después de muchos años de producción teatral, y tampoco había sido reconocido por sus contemporáneos.

En Martínez Ballesteros y Romero Esteo tenemos dos representantes extremos del teatro español de protesta, cada uno a su manera. Para ellos y para todos los demás se puede decir hoy que la época del teatro español de crítica del sistema político ha terminado con el fin de la era de Franco y el comienzo de la democracia en España. Este teatro podría definirse como una válvula de escape y un catalizador de los conflictos sociales y políticos que surgieron en una dictadura específicamente española.

34 Jerónimo López Mozo, Teatro de barrio, teatro campesino. Apuntes, Bilbao, Zero, 1976. 